\title{
A VULNERABILIDADE SOCIOAMBIENTAL NO CONTEXTO DA EXPLORAÇÃO DAS PEDRAS PRECIOSAS E SEMIPRECIOSAS EM NAMANHUMBIR, DISTRITO DE MONTEPUEZ (MOÇAMBIQUE), ENTRE 2004 E 2011
}

\author{
Eduardo Jaime Bata ${ }^{1}$ \\ Zilda Fátima Mariano ${ }^{2}$
}

Resumo: A pesquisa analisou a vulnerabilidade socioambiental nas áreas de exploração do rubi e turmalina, nas aldeias de Nanhupo e Nséue, Distrito de Montepuez, entre 2004 a 2011. A referida análise baseou-se na metodologia de Figueirêdo et al., (2009 e 2010), e consistiu na: a) escolha do sistema e das questões socioambientais, b) identificação dos indicadores $e$ c) definição dos critérios (exposição, sensibilidade e capacidade de resposta). Foi realizada a pesquisa de campo com aplicação de questionários a 49 garimpeiros e 49 moradores nas duas aldeias e a realização de cinco entrevistas com técnicos, diretor e gerente. O Índice Final de Vulnerabilidade Socioambiental nas duas aldeias foi de 3,86, considerado muito alta vulnerabilidade, no qual a exposição $(1,15)$ e capacidade de resposta $(11,29)$ determinaram este valor. $O$ rubi é a pedra preciosa mais explorada, 61\% dos garimpeiros trabalham em minas a céu aberto, e 100\% dos garimpeiros não usam equipamento de segurança no seu trabalho. $O$ inicio do garimpo cogitou o aumento da cesta básica, dificultando o acesso dos produtos básicos pela população mais carente. A pesquisa permitiu compreender a relação entre o garimpo e a vulnerabilidade socioambiental nessas aldeias, bem como a relação desta atividade com o aumento da renda e melhoria das condições de vida dos garimpeiros e dos moradores.

Palavras-chave: Vulnerabilidade Socioambiental; Garimpeiros; Degradação Ambiental; Moçambique.

\section{THE SOCIO- ENVIRONMENTAL VULNERABILITY IN CONTEXT OF SEMI-PRECIOUS AND GEMSTONES MINING, CASE STUDY OF NAMANHUMBIR IN MONTEPUEZ DISTRICT (MOZAMBIQUE), BETWEEN 2004 TO 2011}

\begin{abstract}
The research analysed the socio-environmental vulnerability in areas where gemstones such as ruby and tourmalines are exploited in Nanhupo and Nseue, in Montepuez District, between 2004 and 2011. This analysis was based on the methodology of Figueirêdo et al., (2009 and 2010), and consisted in: a) choosing the system and the socio-environmental questions; b) identifying indicators for assessment; c) defining the criteria (exposition, sensibility and capacity of response). The field research was carried out in Nanhupo and Nseue, where semi-structured questionnaires were applied to 49 miners and 49 local residents, not only this but also 5 surveys were conducted. The final socio-environmental
\end{abstract}

1. Mestre em Geografia, Professor Assistente na Universidade Pedagógica de Nampula-Moçambique (eduardobata1983@gmail.com).

2. Doutora em Geografia pela UNESP, Professora Associada I no programa de Graduação e Pós- Graduação em Geografia da Universidade Federal de Goiás, Campus Jataí (zildadefatimamariano@gmail.com). 
vulnerability index of those villages was 3.86, which makes it high vulnerability were the criteria of exposition $(1,15)$ and capacity of response $(11,29)$ defined this value. The research showed that ruby is the most exploited gemstone, and 61\% of the miners work in opencast mines, in both villages the study indicated that $100 \%$ of the miners work without safety equipment. Therefore, the beginning of mining increased creel making access by the poorest population, in the other hand this research allowed to better understanding the relationship between the gemstones exploitation and environmental vulnerability in these villages, as well as its relationship with income increases and improving living conditions of the miners and the local residents.

Key words: Environmental Vulnerability; Artisanal Miners; Environmental Degradation; Mozambique.

\section{INTRODUÇÃO}

As mudanças nos padrões de produção assistidas nos últimos anos, sobretudo a partir da segunda metade do século XVIII e de forma mais intensa no século XX vêm contribuindo decisivamente para a alteração das relações entre o homem e o ambiente, contribuindo para a degradação ambiental. A nova relação entre o homem e o meio foi marcada pela mecanização, ocupação de áreas consideradas de risco e, por isso, pouco ou quase inabitadas a "humanização" do meio natural, o que propiciou o aumento dos problemas ambientais; a vulnerabilidade de algumas áreas e a periferização ou segregação da população humana mais carenciada e residente nessas áreas.

Assim, a análise da vulnerabilidade dessas áreas permite compreender as relações, as tramas e as transformações socioambientais ocorridas no meio físico, midiatizadas pelas atividades humanas, (dentre as quais a mineração) e a adoção de estratégias que auxiliam na tomada de decisões sobre questões relacionadas à degradação socioambiental.

Em Moçambique, a mineração é praticada em dois níveis: industrial- representada pelos grandes projetos de capital majoritariamente estrangeiro também designado megaprojetos, e a exploração artesanal ou garimpo.

Com relação à contribuição econômica da mineração industrial, incluindo o gás e o petróleo, os dados do Instituto Nacional de Estatística (INE) 2012 apontam que este setor contribuiu com 1,6\%, em 2006, em 2008 com 3\% e em 2011 com 5\% do valor total do Produto Interno Bruto (PIB). 
No país, o garimpo é praticado por significativa fração da população masculina, sobretudo nas regiões centro e norte. Embora o garimpo seja uma atividade que era praticada antes da ocupação colonial portuguesa (1498), este se intensificou após a guerra civil, sobretudo a partir de 1993, devido a um longo período seco e, de baixa produtividade agrícola, a qual coagiu um número considerável da população rural a abandonar temporariamente (período entre a sementeira e a colheita) as atividades agrícolas para dedicar-se ao garimpo do ouro, nas províncias de Manica, e das pedras preciosas, em Nampula e Zambézia (SELEMANE e MOSCA, 2011).

Apesar dos impactos negativos dessas atividades, em Moçambique, grande parte das pesquisas desenvolvidas na área dos recursos minerais, é voltada apenas para análise dos benefícios econômicos da mineração industrial, medido, principalmente pela sua contribuição no PIB. Estes estudos desconsideram a importância, bem como os impactos gerados pelo garimpo em diversas regiões do país.

De acordo com a Lei no 14/2002 (Lei de minas), o garimpo é uma atividade que causa poucos impactos sobre o meio, uma vez que obedece a processos tecnológicos rudimentares e aparentemente pouco nocivos ao ambiente local. Entretanto, considerar o garimpo uma atividade pouco impactante sobre o ambiente parece uma tentativa de mascarar a verdade, pois esta atividade é uma das que mais contribui negativamente para a degradação ambiental nas áreas onde ela é praticada.

Este artigo analisou a vulnerabilidade socioambiental nas áreas de exploração do rubi e turmalina, nas aldeias de Nanhupo e Nséue, Distrito de Montepuez, entre 2004 a 2011 . 0 artigo está estruturado da seguinte forma: introdução, revisão da literatura, material e métodos, resultados e discussão, conclusões e referências bibliográficas.

\section{REVISÃO DA LITERATURA}

A partir década de 1960 e 1970, as questões ambientais passaram a centralizar a atenção de vários pesquisadores, dos acadêmicos e de organismos internacionais, como a Organização das Nações Unidas (ONU), especialmente, com o lançamento do livro Primavera Silenciosa, de Rachel Carson, no qual explica como o uso do Diclorodifeniltricloroetano (DDT) interfere na cadeia alimentar dos animais, incluindo o homem. Portanto, este constituiu uma 
importante reivindicação sobre a degradação ambiental a qual favoreceu o surgimento dos primeiros movimentos ambientalistas.

A escala global e do ponto de vista institucional, o marco inaugural das discussões sobre a degradação ambiental e os seus impactos nas diversas esferas, foi a realização da Conferência de Estocolmo, em 1972. Assim, a evolução das discussões sobre a problemática ambiental foi marcada pela realização de várias cúpulas (Rio 92, Johanesburgo 2002, Rio 2012), nas quais importantes instrumentos norteadores das ações humanas sobre o ambiente foram aprovados. Dentre os instrumentos aprovados ao longo dessas cúpulas, destacam-se a Agenda 21, o Protocolo de Kyoto, a Declaração do Rio de Janeiro sobre o meio ambiente e desenvolvimento, a Convenção sobre mudanças climáticas, entre outros.

$\mathrm{Na}$ esteira da evolução das preocupações com o ambiente, em 1987 foi publicado o Relatório de Brundtland no qual foi apresentado a expressão e o conceito desenvolvimento sustentável, ou seja, aquele desenvolvimento baseado no uso sustentável dos recursos existentes sem, no entanto, comprometer a satisfação das necessidades das gerações vindouras. Concomitantemente, novos conceitos foram utilizados na análise de diversos casos de degradação ambiental, dentre esses conceitos pode-se citar a vulnerabilidade.

Portanto, com base nesses conceitos buscou-se a partir de alguns exemplos, evidenciar a necessidade de uma mudança de atitude da humanidade e a reafirmar que os atuais níveis de degradação ambiental resultam do atual modelo de desenvolvimento econômico e da apropriação da natureza pelo homem em seu beneficio.

\section{VULNERABILIDADE: ORIGEM E CONCEITOS}

A vulnerabilidade tornou-se uma palavra cada vez mais aplicada em diversos contextos sociais e acadêmicos, como a geografia, a demografia, ambiente, economia, saúde, entre outros. Entretanto, em cada um desses campos, a abordagem da vulnerabilidade, expressa distintas realidades, apresentando, por isso, diversas perspectivas de interpretação. A análise da vulnerabilidade compreende o estudo sobre o risco ao qual determinada área, ou comunidade está sujeita, e relaciona-se à capacidade de luta e de recuperação que o individuo ou ecossistema pode apresentar (AYRES, 1999). 
Em sua essência, a palavra vulnerabilidade provém do latim vulnus, vulneris, que sugere a condição de estar ferido, atingindo nas suas capacidades ou mesmo limitado (ADGER, 2006). Segundo Ayres (1999), o conceito e aplicação do termo vulnerabilidade remota do início da década de 1990, quando, pela primeira vez, foi aplicado à saúde pública, no contexto da epidemia da AIDS, com a publicação do livro AIDS in the world, nos EUA. Desde então, o termo foi introduzido em outras áreas de conhecimento, impregnando diversas interpretações e significados.

Atualmente, o conceito de vulnerabilidade é usado nas ciências sociais, embasando políticas públicas voltadas, principalmente, aos setores considerados mais vulneráveis. De acordo Esteves (2011), na ciência geográfica, os primeiros estudos sobre a vulnerabilidade estão associados aos desastres naturais (natural hazards) e avaliação de risco (risk assessment), nos quais a vulnerabilidade não foi tratada enquanto conceito, mas relacionada à noção de capacidade de resposta.

Na ciência geográfica, os debates sobre a vulnerabilidade acrescentam a dimensão espacial visando não só mostrar a inseparabilidade do trinômio espaço, sociedade e vulnerabilidade, como também esclarecer que a vulnerabilidade enquanto um fenômeno dinâmico pode ser mensurado, haja vista que ele ocorre num determinado espaço.

Para Hogan e Marandola Jr. (2005, p. 36), a incorporação do espaço na abordagem sobre a vulnerabilidade,

[...] parte das dinâmicas que configuram uma dada espacialidade, procurando circunscrever sua escala (uma região, uma cidade, um ecossistema), identificando nas interações entre sociedade e natureza os riscos e perigos que atingem o lugar. Não se trata de entender esta espacialidade enquanto substrato físico independente da sociedade. Antes, a abordagem busca unidade de referência para compreender o contexto da produção social do perigo em conexão com o contexto geográfico na delimitação da escala espacial. O resultado desta relação, suas tensões, aberturas, estruturas de proteção e risco, permite identificar a vulnerabilidade.

A vulnerabilidade tem sido estudada por vários autores e nas diversas perspectivas no mundo. No Brasil, por exemplo, pesquisadores como Hogan e Marandola Jr. (2005), Gamba (2011), e Santos (2011) e outros estudaram sobre a vulnerabilidade e o risco. O âmago dos 
debates está situado em duas áreas: a geografia e a demografia, cada uma delas utilizando o seu próprio arcabouço conceitual para delinear situações de vulnerabilidade.

Em Moçambique, a discussão sobre a vulnerabilidade é escassa; a única instituição que comumente usa este termo é o Instituto Nacional de Gestão de Calamidades (INGC), aludindo à população residente em áreas propensas a ocorrência de cheias, ciclones, secas, principalmente, nas regiões sul e centro do país. Ratificando esta posição, Waterhouse (2010, p. 99) explica que,

[...] em Moçambique, tanto as políticas públicas como as práticas correntes sugerem uma compreensão pouco abrangente de "vulnerabilidade" (grifo do autor), vista não só como uma característica inata de grupos sociais específicos, mas também como uma característica típica de pessoas afetadas por catástrofes naturais.

A vulnerabilidade refere-se à suscetibilidade em ser afetado por alguma coisa. Do ponto de vista científico, as abordagens sobre a vulnerabilidade assumem a polissemia do conceito, tornando-a passível de investigação pelas diversas áreas do conhecimento cientifico (ALVES, 2005).

Segundo Hogan e Marondola Jr. (2005, p. 35), “a vulnerabilidade é evocada na tradição de estudos sobre a pobreza enquanto um novo conceito forte, na esteira dos utilizados em outros tempos como exclusão/inclusão, marginalidade, apartheid, periferização, segregação, dependência, entre outros".

De acordo com Blaikie et al., (1994), citados por Alves (2005), a vulnerabilidade é definida como as características de uma pessoa ou grupo em termos de sua capacidade de antecipar, lidar com, resistir e recuperar-se dos impactos de um desastre. A vulnerabilidade é também compreendida como produto da exposição física a um perigo natural (natural hazard), a capacidade humana para recuperar-se dos impactos negativos, em uma interação entre o risco, as características e o grau de exposição da população residente nesse lugar.

Portanto, na perspectiva destes autores, a vulnerabilidade deve ser compreendida como a interação entre o risco, contexto geográfico, percepção e experiência social, ou seja, a vulnerabilidade dá-se pela interação entre o risco, perigo potencial do lugar, e o contexto geográfico no qual se insere a experiência e a percepção social. 
De acordo com Adger (2006), a vulnerabilidade é geralmente retratada em termos negativos, ou seja, como a suscetibilidade de ser prejudicado, ou melhor, é o grau em que um sistema é incapaz de lidar com os efeitos adversos (da mudança). Assim, a vulnerabilidade é frequentemente definida como sendo constituída por um ou mais componentes, que incluem a exposição, a sensibilidade às perturbações ou tensões externas e a capacidade de adaptação.

\section{AVALIAÇÃO DA VULNERABILIDADE}

A avaliação da vulnerabilidade tem tornado-se uma importante ferramenta analítica para descrever o estado de suscetibilidade, a impotência e a marginalidade dos sistemas físicos e sociais. A análise da vulnerabilidade permite aferir as condições, bem como o grau de suscetibilidade dos sistemas à degradação ambiental. Portanto, potenciar o uso desta ferramenta na gestão, para auxiliar na tomada de decisão, evitando e/ou minimizando os efeitos dos eventos catastróficos sobre uma determinada comunidade, coloca-se como um novo desafio para diversos pesquisadores (HELTBERG et al., 2008).

$\mathrm{Na}$ avaliação da vulnerabilidade dos ecossistemas à degradação ambiental, apontam-se como importantes contribuições os seguintes estudos: a) Figueirêdo et al., (2009), com o método de avaliação do desempenho ambiental de inovações tecnológicas agroindustriais: Ambitec - ciclo de vida, no desempenho ambiental do substrato de coco verde; b) Figueirêdo et al. (2010), na análise da vulnerabilidade ambiental das pressões associadas à adoção de inovações agroindustriais, o qual foi adaptado para esta pesquisa.

Ainda sobre esta temática, destacam-se os seguintes estudos: a avaliação da vulnerabilidade dos ecossistemas à mudança no uso da terra, de Metzger et al., (2006), e avaliação da vulnerabilidade humana às mudanças climáticas, realizado por Heltberg et al., (2008). Entretanto, apesar do volume das pesquisas nesse campo, as suas abordagens, assim como os métodos utilizados, nem sempre são convergentes.

Diante dessas divergências e/ou limitações, Villa Mc Leod (2002) e Adger (2006) apontam que, para avaliação da vulnerabilidade de um sistema, é importante considerar as seguintes etapas: a) a definição do conceito de vulnerabilidade e b) a escolha do sistema e dos indicadores ambientais. 


\section{MATERIAL E MÉTODO}

\section{Caracterização da área de estudo}

A área de estudo situa-se no Posto Administrativo de Namanhumbir, Distrito de Montepuez (DM), Província de Cabo Delgado - Moçambique. O Posto Administrativo de Namanhumbir (PAN) localiza-se a Leste da cidade de Montepuez, com os seguintes limites: Norte, o Distrito de Meluco; Sul, o Distrito de Montepuez; Leste, o Distrito de Ancuabe, Oeste, a cidade de Montepuez (Figura 1).

A divisão administrativa de Namanhumbir compreende as localidades de Namanhumbir Sede, na qual se situam as aldeias de Nanhupo e Nséue (locais da pesquisa) e Mpupene, que integra as aldeias de Ntorro e 25 de Setembro. No total, Namanhumbir tem 22.245 habitantes, 10.793 são homens e 11.452 mulheres, distribuídos pelas duas localidades rurais (PLANO ESTRATÉGICO DE DESENVOLVIMENTO DISTRITAL, 2007).
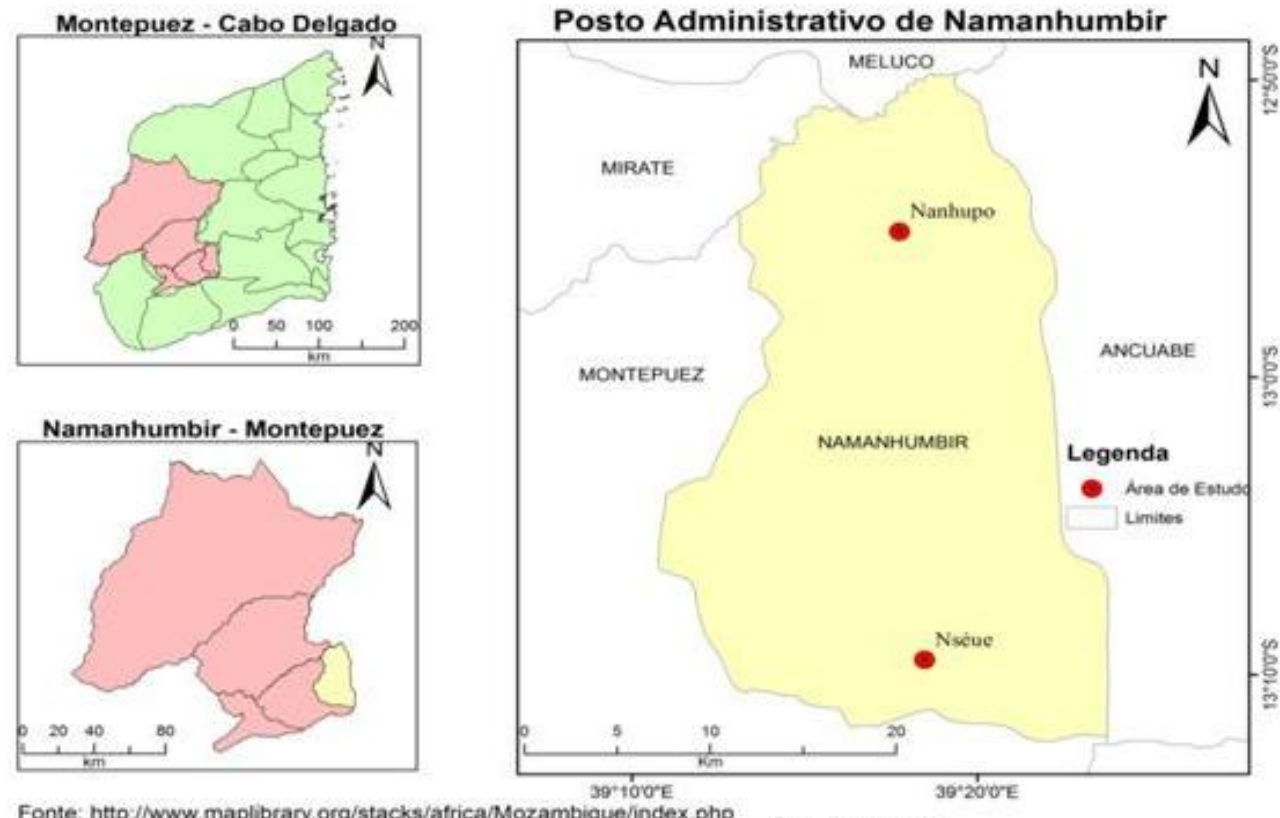

Fonte: http: /Nww. maplibrary org/stacks/africa/Mozarm

Figura 1: Localização geográfica de Namanhumbir, Distrito de Montepuez- Moçambique. Fonte: Bata e Mariano (2013)

Análise da vulnerabilidade socioambiental nas aldeias de Nanhupo e Nséue, Distrito de Montepuez

A avaliação da vulnerabilidade socioambiental foi baseada na metodologia de Figueirêdo et al., (2009 e 2010), e adaptada ao objeto de estudo desta pesquisa, e consistiu nas seguintes etapas: a) escolha do sistema e das questões socioambientais; b) identificação dos 
indicadores na avaliação e c) definição dos critérios (exposição, sensibilidade e capacidade de resposta). A referida avaliação foi realizada nas aldeias de Nanhupo e Nséue, considerando a suscetibilidade à degradação socioambiental das comunidades nas quais se exploram as pedras preciosas e semipreciosas.

Considerando o conceito de vulnerabilidade de Adger (2006), a exposição das aldeias referese às pressões exercidas e as transformações induzidas pela mineração e outras atividades sociais sobre o ambiente. A sensibilidade destas foi avaliada ponderando as características do meio, ou seja, a existência e/ou o acesso aos serviços básicos sociais, bem como a existência de áreas sensíveis à degradação ambiental e protegidas por lei.

Já a capacidade de resposta foi aferida considerando a adoção de ações que visam à conservação ambiental, e o provimento de serviços básicos à população.

Portanto, a avaliação do Índice Final de Vulnerabilidade Socioambiental (IFVSA), foi realizada com base em 21 indicadores, normalizados e agregados em três critérios: exposição, sensibilidade e capacidade de resposta (Quadro 1). 


\begin{tabular}{|c|c|c|c|c|}
\hline $\begin{array}{l}\text { Questốes ambientais } \\
\text { de Figueirềlo et al. } \\
\text { (2010) }\end{array}$ & $\begin{array}{l}\text { Questốes ambientais } \\
\text { adaptadas de Figueirềdo et } \\
\text { al. (2010) }\end{array}$ & $\begin{array}{l}\text { Indicadores de Figueirêdo et } \\
\text { al. (2010) }\end{array}$ & $\begin{array}{l}\text { Indicadores adaptados de } \\
\text { Figueirêdo et al. (2010) }\end{array}$ & Critérios \\
\hline \multirow[t]{3}{*}{$\begin{array}{l}\text { Erosão } \\
\text { Escassez hidrica } \\
\text { Perda da biodiversidade } \\
\text { Poluị̧̄o das aguas } \\
\text { Salinização sodificação }\end{array}$} & 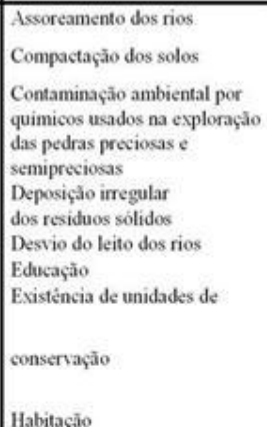 & $\begin{array}{l}\text { Atividade agropecuária } \\
\text { Area reservada à atividade } \\
\text { industrial } \\
\text { Demanda hidrica per capita } \\
\text { Geração de lixo per capita } \\
\text { Geraçăo de esgoto per capita }\end{array}$ & $\begin{array}{l}\text { Arrea reservada à mineraç̃o } \\
\text { Área reservada à atividade } \\
\text { agropecuária } \\
\text { Area reservada à atividade } \\
\text { industrial } \\
\text { Abastecimento de agua nas } \\
\text { casas residenciais } \\
\text { Numero de escolas } \\
\text { Destruị̧ăo da vegetação } \\
\text { Represamento dos rios e lagos } \\
\text { para o uso da agua na } \\
\text { exploraçăo das pedras } \\
\text { preciosas e semipreciosas }\end{array}$ & $\frac{\frac{9}{d}}{\frac{d}{L}}$ \\
\hline & $\begin{array}{l}\text { Perda da vegetaçào nativa } \\
\text { Saùde }\end{array}$ & $\begin{array}{l}\text { Aridez do clima } \\
\text { Aptidão agricola } \\
\text { Areas prioritarias } \\
\text { para conservação } \\
\text { Intensidade pluviométrica } \\
\text { Qualidade da água } \\
\text { para irrigaçăo }\end{array}$ & $\begin{array}{l}\text { Acesso à água potável } \\
\text { Contaminação dos garimpeiros } \\
\text { pelo manuscio } \\
\text { de produtos quimicos (Hg) } \\
\text { usados na exploração das } \\
\text { pedras preciosas e } \\
\text { semipreciosas } \\
\text { Local e procedimentos antes } \\
\text { da deposição do livo } \\
\text { doméstico } \\
\text { Nümero médio de membros } \\
\text { por agregado familiar } \\
\text { Doenças dos garimpeiros } \\
\text { Tipo de labitaçăio }\end{array}$ & 竎 \\
\hline & & $\begin{array}{l}\text { Acesso à coleta e destino } \\
\text { adequado do lixo } \\
\text { Acesso a esgotamento } \\
\text { sanitario } \\
\text { Acesso à àgua tratada } \\
\text { Areas em unidades de } \\
\text { conservação } \\
\text { Conservą̧ào do solo } \\
\text { Disponibilidade hidrica per } \\
\text { capita } \\
\text { IDH-M }\end{array}$ & $\begin{array}{l}\text { Casas com fossa séptica e com } \\
\text { aceso a rede de esgoto } \\
\text { Casas com acesso ao serviço } \\
\text { de coleta de liso doméstico } \\
\text { Conservaçăo do solo } \\
\text { Nümero de fontenários } \\
\text { operacionais } \\
\text { Número postos de saúde } \\
\text { Numero de habitantes por } \\
\text { médico } \\
\text { Valor médio da cesta básica } \\
\text { Exístència de unidades de } \\
\text { conservaçắo }\end{array}$ & 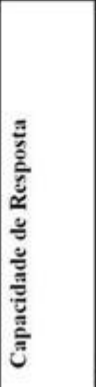 \\
\hline
\end{tabular}

Quadro 1: Questões ambientais, indicadores e critérios que compõem o IFVSA

Fonte: Adaptado de Figueirêdo et. al. (2009; 2010).

A escolha das questões socioambientais e dos indicadores deveu-se à disponibilidade de base de dados com os indicadores (tipo de habitação; número de habitantes por médico; número médio de membros por agregado familiar; número de fontenários operacionais e número de escolas), fornecidas pelo INE, Ministério da Saúde (MISAU), Ministério da Educação (MEC), e pelos relatórios de atividades, Plano Estratégico de Desenvolvimento (PEDD), Plano Estratégico de Educação e Cultura (PEEC), e os outros foram obtidos na pesquisa de campo. Entretanto, devido à falta de alguns dados referentes às duas aldeias, parte dos dados apresentados é do Distrito de Montepuez.

\section{Normalização dos indicadores}

A normalização de cada indicador foi realizada considerando dois tipos de indicadores: qualitativos e quantitativos. No critério de exposição os indicadores quantitativos foram: área reservada à mineração; área reservada à atividade agropecuária; área reservada à 
atividade industrial; destruição da vegetação e represamento dos rios, no critério de sensibilidade foram: doenças dos garimpeiros; número médio de membros por agregado familiar; contaminação dos garimpeiros pelo manuseio de produtos químicos $(\mathrm{Hg})$, e na capacidade de resposta foram: valor médio da cesta básica e número de habitantes por médico, ponderando que quanto maior seu valor, maior a vulnerabilidade, e calculado pela equação (1a).

valor $_{i}=\left(\frac{\text { Indicador }_{i}-\text { Valor }_{\text {min }}}{\text { Valor }_{\text {máx }}-\text { Valor }_{\min }}\right)+1$

Para os indicadores do tipo quanto menor seu valor, maior a vulnerabilidade ambiental, foram considerados no critério de exposição: número de escolas e casas sem abastecimento de água da rede geral. No critério de sensibilidade, considerou-se: casas com fossa séptica e acesso à rede de esgotos e acesso à água potável e no critério de capacidade de resposta, foram considerados: casas com acesso ao serviço de coleta de lixo doméstico, conservação do solo, número de fontenários operacionais e número de postos de saúde, calculada pela equação (1b).

Valor $_{\mathrm{i}}=\left(\frac{\text { Valor }_{\text {máx }}-\text { indicador }_{\mathrm{i}}}{\text { Valor }_{\text {máx }}-\text { Valor }_{\min }}\right)+1$

Onde,

- Valor $_{\mathrm{i}}=$ valor normalizado do indicador

- Valor máx. = valor máximo de ser alcançado pelo indicador de vulnerabilidade;

- Indicador = valor original que pode ser assumido por um indicador;

- Valor min. = valor mínimo possível de ser alcançado pelo indicador de vulnerabilidade

- $\mathrm{i}=$ indicador dentre os utilizados no método (Tabela 1).

Após a seleção dos indicadores, estes foram normalizados utilizando uma transformação linear em uma escala que varia entre 1 a 2 (Tabela 1 ). 


\begin{tabular}{ll}
\hline Vulnerabilidade & Valor \\
\hline Muito baixa & $1-1,2$ \\
Baixa & $1,2-1,4$ \\
Média & $1,4-1,6$ \\
Alta & $1,6-1,8$ \\
Muito alta & $1,8-2$ \\
\hline
\end{tabular}

Quadro 2: Níveis de Vulnerabilidade.

Fonte: Figueirêdo et al., (2010).

\section{Agregação dos indicadores em critérios}

Os indicadores de vulnerabilidade foram integrados nos critérios de exposição, sensibilidade e capacidade de resposta, de forma linear, pela média dos indicadores pertencentes a cada classe, ponderando que cada indicador tem o mesmo peso na composição do critério ao qual pertence (FIGUEIRÊDO et al., 2010) (Equação 2).

$$
\text { Critério }_{\mathrm{c}}=\sum_{\mathrm{i}=1}^{\mathrm{n}} \text { peso }_{\mathrm{i}} * \text { vulnerabilidade_indicador }_{\mathrm{i}}
$$

Onde,

- Critério $c=$ valor da vulnerabilidade em um dos critérios (exposição, sensibilidade e capacidade de resposta);

- c = critério em análise (1 - exposição; 2 - sensibilidade e 3 - capacidade de resposta);

- Peso = peso do indicador no critério;

- Vulnerabilidade_indicador = valor normalizado do indicador de vulnerabilidade.

\section{Agregação dos critérios no Índice Final de Vulnerabilidade Socioambiental (IFVSA)}

O IFVSA foi composto pela média ponderada dos valores em cada critério pelo peso de cada um. Considera-se que cada critério que compõem o IFVSA tenha o mesmo peso na composição do índice, uma vez que todos são importantes na avaliação da vulnerabilidade de um sistema à degradação ambiental (FIGUEIRÊDO et al., 2010) (Equação 3).

$$
\text { IFVSA }=\sum_{\mathrm{i}=1}^{3} \text { peso }_{\mathrm{c}} * \text { critério }_{\mathrm{c}}
$$

Onde, 
- $\quad$ IFVSA = índice final de vulnerabilidade socioambiental.

- Peso c = peso do critério na formação do índice;

- Critério $c=$ valores do critério c (1 - exposição; 2 - sensibilidade e 3 - capacidade de resposta).

\section{Trabalho de Campo (TC)}

A pesquisa de campo foi realizada no período de março a julho de 2013, em Namanhumbir, especificamente nas aldeias de Nanhupo e Nséue, e nas cidades de Montepuez, Pemba, e Maputo. Nesta fase, foram desenvolvidas as seguintes atividades: a aplicação dos questionários a 49 garimpeiros e 49 moradores, visita às minas de Nséue e da Empresa Montepuez Ruby Mining (MRM) e realização de cinco (5) entrevistas: com o diretor; o técnico ambos dos Serviços Distritais das Atividades Econômicas de Montepuez (SDAEM), com o gerente residente da MRM, com o técnico da Direção Provincial dos Recursos Minerais e Energias (DPRME) e com a técnica da Direção Provincial para Coordenação e Ação Ambiental (DPCAA), todos da província de Cabo Delgado. O roteiro de entrevistas e dos questionários foi submetido ao Comitê de Ética e Pesquisa da Universidade Federal de Goiás para avaliação e verificação das adequações aos princípios éticos em pesquisa nesta Universidade e foi registrado com protocolo n.053/13.

\section{RESULTADOS E DISCUSSÃO}

\section{Análise do Índice Final de Vulnerabilidade Socioambiental (IFVSA), em Namanhumbir}

A análise da vulnerabilidade socioambiental possibilita a compreensão do estado de estresse no qual determinado sistema está sujeito, bem como a capacidade deste para lutar contra os efeitos adversos. Ou seja, a avaliação da vulnerabilidade permite descrever o estado de susceptibilidade, a impotência, a marginalidade dos sistemas físicos e sociais, e garante a aferição das condições e do grau de suscetibilidade dos sistemas à degradação ambiental.

Na Tabela 2, observa-se que o IFVSA das duas aldeias foi de 3,86, classificada como muito alta vulnerabilidade, e superior ao da Tabela 1. Assim, os indicadores número de escolas $(3,44)$, abastecimento de água nas casas residenciais $(2,00)$, e destruição da vegetação $(2,00)$ no critério de exposição, são os que apresentaram maior valor de vulnerabilidade. 
Segundo dados da pesquisa de campo, $95 \%$ dos garimpeiros e moradores apontaram a destruição da vegetação como o principal problema ambiental em Nanhupo e Nséue. A depredação da vegetação é um fator potencial na degradação ambiental, visto que acarreta a perda de biodiversidade e a exposição dos solos aos processos erosivos, com consequente escassez dos solos para a prática da agricultura (Figura 2).

De acordo com o PEEC (2010), o parâmetro ideal de assistência à educação é de cinco escolas para cada 4.500 habitantes. Dados da pesquisa de campo revelaram que em Namanhumbir existem apenas quatro escolas para toda população do PA, valor inferior ao proposto pelo PEEC, além de que não existe nenhuma escola do ensino secundário, obrigando assim, parte significativa dos alunos que terminam o Ensino Primário do Segundo Grau (EP2) a irem estudar em outros Distritos, ou mesmo em outras províncias do País.

No geral, a população de Namanhumbir não tem acesso à água encanada, nem da rede geral; assim, o abastecimento de água é feito por meio de poços a céu aberto e fontenários.

No critério de sensibilidade, o indicador tipo de habitação $(1,11)$ foi o que apresentou maior valor de vulnerabilidade em comparação com os demais indicadores deste critério. De acordo com o INE (2012), 97,9\% das habitações do Distrito de Montepuez foram construídas de material precário, ou seja, com paus, bambus, cobertas de capim e as paredes revestidas de adobe.

Nas duas aldeias, 95\% das habitações foram construídas de material precário, e não está ligada a rede de esgotamento sanitário (Figura 2). 


\begin{tabular}{|c|c|c|c|c|c|c|}
\hline \multirow[b]{2}{*}{ Criterio } & \multirow[b]{2}{*}{ Ind cadores } & \multirow[b]{2}{*}{ Unida de de medi da } & Valor medilo & \multicolumn{3}{|c|}{ Vulnera billida os ambiantal } \\
\hline & & & do Inacador & Indicador & criterio & IFVSA \\
\hline \multirow{7}{*}{ Exposiçãa } & Area reservada à mineraçăo & \% (percentual da área do P.A reservada à mineraçăo) & $51,79 \%$ & 0,09 & 1,15 & 3,86 \\
\hline & Area reservada à atividade industrial & $\%$ (percentual da área do P.A reservada à ind ústia) & $22,85 \%$ & 0,75 & & \\
\hline & Area reservada à atividade agropecuária & $\begin{array}{l}\text { \% (percentual da área do P.A reservada à } \\
\text { agropecuária) }\end{array}$ & $72,27 \%$ & $-1,21$ & & \\
\hline & Número de escolas & Total de escolas existentes no P.A & 5,00 & 3,44 & & \\
\hline & $\begin{array}{l}\text { Abastecimento de água nas casas } \\
\text { residenciais }\end{array}$ & $\%$ (percentual da populaçăo com acesso à água) & $0 \%$ & 2,00 & & \\
\hline & Represamento de rios e lagos para a & $\%$ (percentual de represamento de rios e lagos) & & & & \\
\hline & Destruiçăa da vegetaçăo & $\%$ (percentual da destruiçăo da vegetaçăo no P.A) & $0 \%$ & 1,00 & & \\
\hline \multirow{6}{*}{ Sensibilidade } & $\begin{array}{l}\text { Acesso à água potável } \\
\text { Número de membros por agregado }\end{array}$ & $\begin{array}{l}\text { \% (percentual da popul. com acesso á água no P.A) } \\
\text { Totalimédio dos membros por agregado familiar }\end{array}$ & $20 \%$ & 1,00 & $-0,85$ & \\
\hline & $\begin{array}{l}\text { familiar } \\
\text { Tipo de habitacão }\end{array}$ & $\%$ (percentual de habitacăo constuida de material & 7 & $-0,79$ & & \\
\hline & & precário) & $97,90 \%$ & 1,11 & & \\
\hline & $\begin{array}{l}\text { Contaminaçào dos garimpeiros por } \\
\text { quimicos } \\
\text { Local e procedimentos antes da }\end{array}$ & $\begin{array}{l}\% \text { (percentual de garimpeiros contaminados por } \\
\text { quimicos) } \\
\text { Total de acóes realizadas pelos moradores antes }\end{array}$ & $0 \%$ & 1,00 & & \\
\hline & deposiçào do lice. & deposiçáo do loo doméstico & $0 \%$ & 1,00 & & \\
\hline & Doenças dos garimpeiros & Doenças que afetam os garimpeiros & 6 & $-8,44$ & & \\
\hline \multirow{8}{*}{$\begin{array}{l}\text { Capacidade de } \\
\text { Resposta }\end{array}$} & $\begin{array}{l}\text { Casas com fossa séptica e acesso à rede } \\
\text { de esgoto } \\
\text { Casas com acesso a coleta do lvo }\end{array}$ & $\begin{array}{l}\% \text { (percentual de casas com acesso a fossa sépfica e } \\
\text { egoto) } \\
\% \text { (percentual de casas com acesso a coleta de fico }\end{array}$ & $0 \%$ & 2,00 & 11,29 & \\
\hline & doméstico & domés6co) & $0 \%$ & 2,00 & & \\
\hline & Exstencla de unidados de conservaçà & $\begin{array}{l}\text { \% (percentual a area ocupada pelas unidades d } \\
\text { conservaçáo no PA) }\end{array}$ & $0 \%$ & 2,00 & & \\
\hline & Número de postos de saúde & Total de postos de saúde existentes no PA & 3,00 & 6,11 & & \\
\hline & Valor da cesta básica & Valor da cesta básica & 500,00 & 16,15 & & \\
\hline & Número de habitantes por médico & Total de habitantes por médico no P.A & 1000,00 & 51,47 & & \\
\hline & Nimero de fontenários em uncionamento & Total de bntenário em funcionamento no P.A & 28,00 & 9,00 & & \\
\hline & Conservaçăo do solo & \% (percentual de açŏes para a conservạ̧ăo do solo) & $40 \%$ & 1,60 & & \\
\hline
\end{tabular}

Tabela 1: Cálculo do IFVSA utilizando a metodologia de Figueirêdo et al. (2010) Fonte: Trabalho de campo (Abril / 2013).

Org.: Autor (2014).

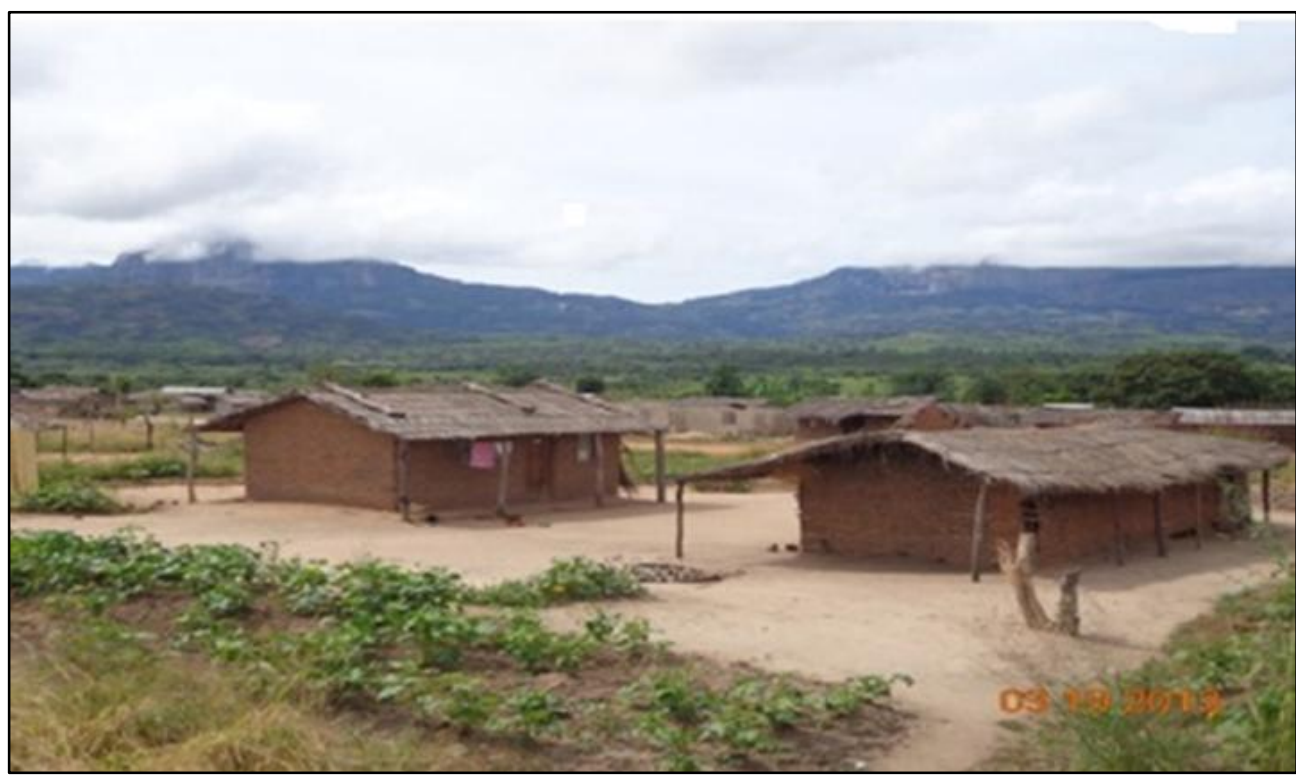

Figura 2: Tipo de habitação predominante nas aldeias de Nanhupo e Nséue.

Fonte: Trabalho de campo (Abril /2013)

Autor: Bata, Eduardo (2013)

A baixa capacidade de resposta, com consequente alta vulnerabilidade deste critério $(11,29)$

(Tabela 2), deveu-se, principalmente, aos indicadores número de habitantes por médico

$(51,47)$, valor da cesta básica $(16,15)$ e número de fontenários em funcionamento $(9,00)$.

Segundo o MISAU (2010), em Moçambique, 01 médico deve atender 10.000 habitantes, 
valor muito alto em comparação ao definido pela Organização Mundial de Saúde (OMS), que é de 01 médico para cada 1.000 habitantes.

Com relação ao valor da cesta básica, este aumentou de 500,00 MT, antes do inicio do garimpo, para 2.000,00MT (MT- metical, unidade de moeda usada em Moçambique, 1 dólar americano equivale a 29 MT, no câmbio de 22/07/2013). O início da exploração das pedras preciosas gerou uma maior demanda por diversos serviços e, sobretudo, pelos produtos alimentícios tais como: óleo, açúcar, sabão, entre outros.

Mosca e Selemane (2011) explicam que, o começo de algumas atividades ou a implantação de algum projeto numa área suscita uma procura segmentada que afeta negativamente a população de menor rendimento, devido ao aumento dos preços dos produtos alimentares localmente produzidos, tais como o milho, a carne, vegetais e alguns bens importados, o que gera um agravamento do custo de vida, com efeitos sobre os mais pobres e com aprofundamento das desigualdades sociais.

Em Namanhumbir e, principalmente em Nanhupo e Nséue, a descoberta do rubi e de outras pedras preciosas veio agravar o custo de vida, dificultando, assim, o acesso a alguns produtos da primeira necessidade não obtidos diretamente na agricultura. De acordo com os dados da pesquisa de campo, entre 2009 e meados de 2011, o preço da cesta básica foi superior a 3.000,00MT, o que comprova que o início da exploração das pedras preciosas cogitou o aumento do custo de vida, agravando ainda mais as condições de vida da população local. Debruçando-se sobre os impactos do garimpo do rubi o Entrevistado Diretor (ED), por exemplo, apontou que,

[...] o início do garimpo do rubi e a chegada de muitos estrangeiros aqui em Namanhumbir não trouxe nenhuma vantagem, quando muito isso só veio agravar o custo de vida, o nível de vida subiu, mudou o senso das pessoas, principalmente dos mais jovens que tiveram de abandonar a escola para trabalhar para os estrangeiros [...], os produtos da primeira necessidade mudaram tanto, por exemplo, $25 \mathrm{~kg}$ de arroz de qualidade custam em média $800,00 \mathrm{MT}$ e nem todas as famílias conseguem comprar, pois estas dependem da venda dos produtos da machamba [roça na terminologia brasileira], portanto, em geral houve inflação nos preços, antes a cesta básica custava menos do que custa hoje [...] antes do garimpo os preços eram razoáveis do que estão hoje, [...] em 2009, no auge do garimpo em Namanhumbir um refresco chegou a custar 30,00MT a garrafa e um frango assado custava 300,00MT. 
De acordo com a Política Nacional de Águas (2008), o nível mínimo de acesso à água pela população é de uma (01) fonte equipada com bomba manual, para 500 pessoas. Segundo os Serviços Distritais de Planeamento e Infraestruturas (SDPI), 2012, em Namanhumbir existem 60 fontenários equipados com bomba manual; destes 32 encontram-se avariados e 28 em funcionamento. Portanto, o maior número de fontenários (32) avariados corrobora não só para o consumo de água proveniente dos poços caseiros, sem proteção e sem prévio tratamento, como também para uma maior pressão das poucas fontes existentes (Figura 3).

O principal fator de pressão para os fontenários de Nanhupo e Nséue é a existência de maior número de utentes (moradores) para um número reduzido de fontenários em funcionamento, baixo nível de controle e poucos cuidados dos utentes, bem como a deficiente manutenção e reposição das peças danificadas. Por sua vez, as respostas sociais que mitigariam esta questão socioambiental relacionam-se com a alocação de mais recursos financeiros na construção de mais fontenários, reabilitação dos fontenários avariados, e investimentos na construção da rede geral de abastecimento de água à população de Namanhumbir, sobretudo a de Nanhupo e Nséue.

Segundo o Censo (2007), 76\% da população do Distrito de Montepuez consome água proveniente dos poços caseiros sem bomba manual (céu aberto). Por sua vez, em Nanhupo e Nséue $65,3 \%$ dos moradores utilizam água dos poços para diversas atividades do cotidiano.

Haja vista que parte significativa dos poços a céu aberto existentes nas residências das duas aldeias, além de não beneficiar-se de limpeza regular por parte dos moradores, está localizada próximo às latrinas, o que favorece a contaminação da água e a proliferação de doenças de veiculação hídrica, sobretudo na época chuvosa.

Assim, as principais pressões que comprometem a qualidade dos serviços sanitários em Nanhupo e Nséue são: a existência de menor número de unidades sanitárias e com poucos serviços ofertados (consultas externas), considerável parte da população residindo em áreas sem unidades sanitárias e inexistência de médicos para atender a população nas duas aldeias. 


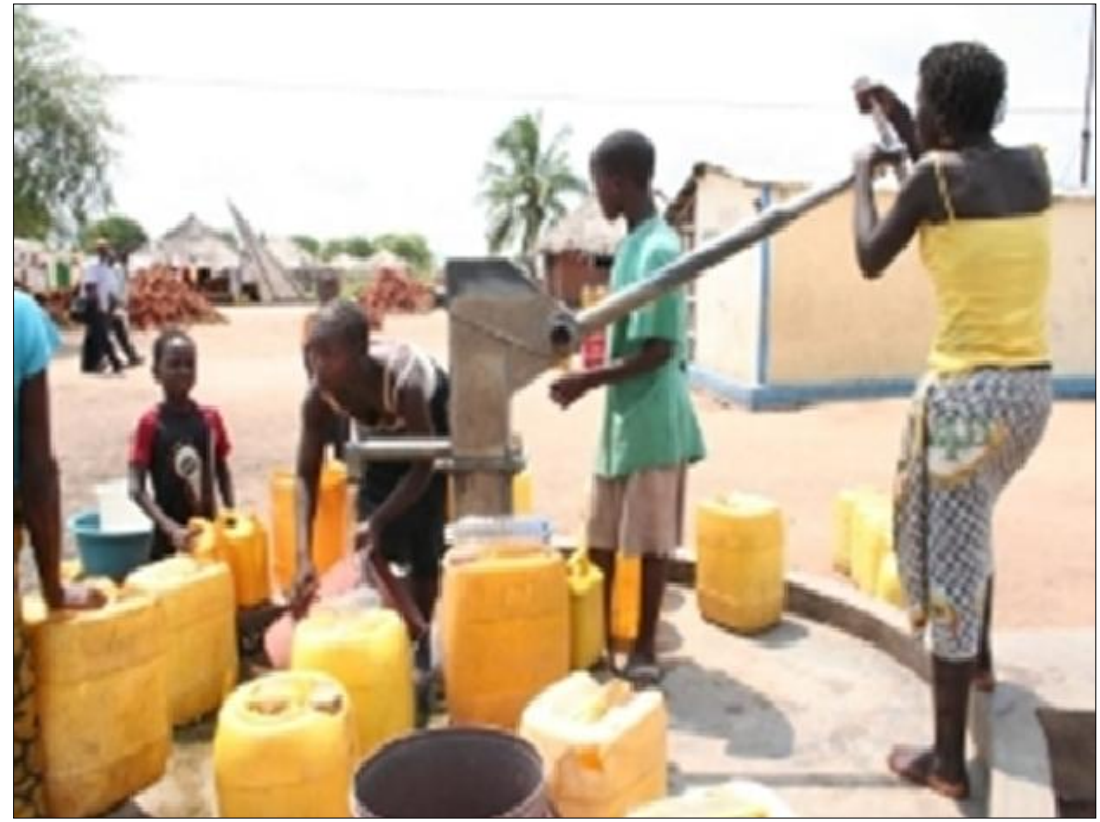

Figura 3: Moradores de Nséue num fontenário público.

Fonte: Trabalho de campo (Abril /2013).

Autor: Bata, Eduardo (2013).

\section{Análise da Vulnerabilidade Socioambiental em Nanhupo e Nséue, a partir dos questionários aplicados aos garimpeiros e moradores}

\section{Exploração das pedras preciosas e semipreciosas: principais intervenientes}

Em Nanhupo e Nséue, a exploração das pedras preciosas e semipreciosas é muito recente (2008), o seu início está relacionado com a descoberta do rubi por um madeireiro furtivo, que se dedicava ao corte de madeira em uma área de caça concessionada à Mwirit, bem como à vinda de cidadãos estrangeiros, principalmente oriundos da Tanzânia, Mali, Senegal, Nigéria e Guiné. Os estrangeiros, inicialmente se estabeleceram em Namanhumbir como comerciantes, e mais tarde, tornaram-se os patrocinadores do garimpo ilegal das pedras preciosas, sobretudo do rubi.

A exploração das pedras preciosas, apesar de ser recente nessas aldeias, carrega consigo as velhas práticas herdadas de outros lugares que, seguramente, denotam um processo ilegal e precário, pois a lavra destas é feita sem a observância dos cuidados mínimos com o ambiente e realizada majoritariamente por jovens entre18 e 35 anos, tal como evidenciaram os dados da pesquisa de campo, que apontam que dos 49 garimpeiros, $87,7 \%$ têm entre 18 a 35 anos, e $12,3 \%$ entre 40 a 45 anos.

Na Figura 4, nota-se que o rubi é a pedra preciosa mais explorada; em seguida, a turmalina, confirmado também pelo relatório de atividades da MRM, que refere que o rubi e a 
turmalina são as pedras preciosas mais exploradas em toda a área concessionada à Empresa, ratificado também pelo EG (2013), que assinalou que “[...] a área em que está sendo explorado presentemente, o que mais se explora é o rubi [...], em outras áreas da nossa concessão, temos outros minerais, como a turmalina e águas marinhas."

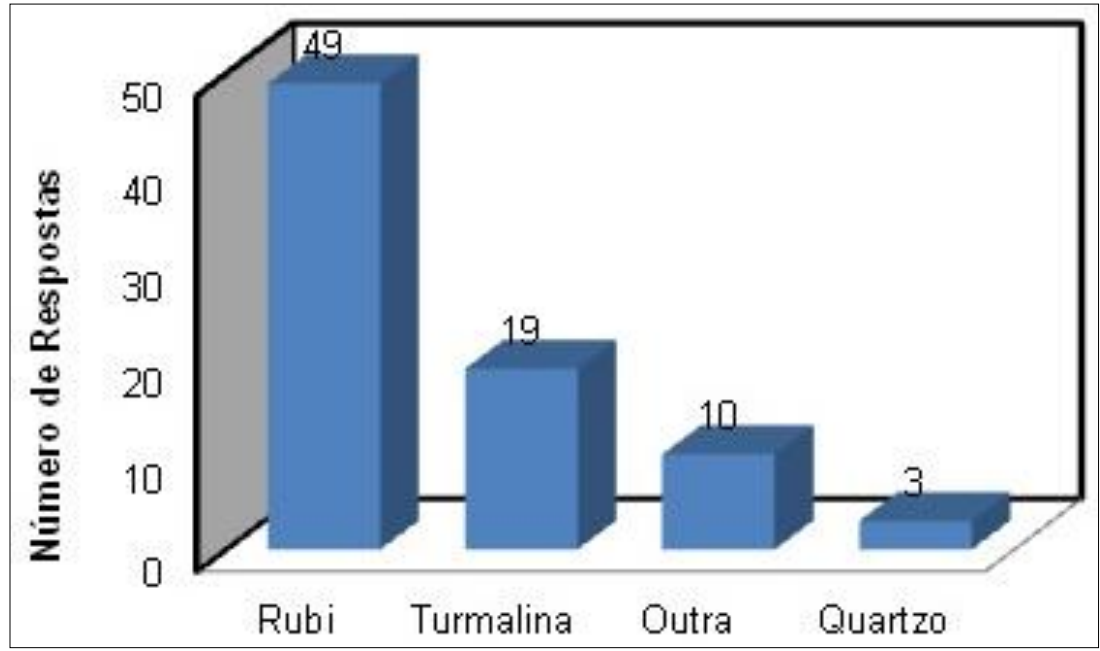

Figura 4: Tipo de pedras preciosas exploradas em Namanhumbir- DM Fonte: Trabalho de campo (Abril /2013) Autor: Bata, Eduardo (2013).

O caráter informal da exploração das pedras preciosas em Nanhupo e Nséue, aliado a não observância das regras de segurança e das condições de trabalho, define a natureza, as contradições e os impactos desta atividade sobre as condições socioambientais dessas aldeias, bem como as transformações socioespaciais inerentes a esta atividade. De acordo com os dados da pesquisa de campo, $61 \%$ dos garimpeiros realizam os seus trabalhos em minas a céu aberto, $25 \%$ em minas que envolvem a abertura de galerias e $14 \%$ dos garimpeiros realiza suas atividades em minas a céu aberto e em poços.

Com relação às medidas de segurança no trabalho, os 49 garimpeiros (100\%) responderam não usar nenhum equipamento de segurança durante o seu trabalho, tal como explicou o GQ35 (2013) que,

[...] Muitos de nós entramos na mina sem nenhum equipamento, apenas com uma camisa de manga comprida para minimizar o sofrimento e evitar muitas feridas às vezes sem camisa isso nos dias de muito sol, de chinelos, às vezes descalços e com uma lanterna para podermos iluminar [...] lá dentro da mina não se pode virar, procuramos seguir a direção do filão, por isso as covas não tem direção.

Portanto, o depoimento deste garimpeiro confirma a situação vivenciada na mina de Nanhupo e Nséue (Figuras 5a e 5b) na qual grande parte dos garimpeiros trabalha sem 
camisa e descalços. As precárias condições de trabalho da grande parte dos garimpeiros nas duas aldeias divergem completamente com o previsto nos artigos 228 e 229 da Lei no $14 / 2002$, que recomenda que,

Os operadores artesanais e os garimpeiros devem usar equipamentos de proteção individual adequado ao trabalho a desenvolver e sempre que os trabalhadores desmontarem minério em frentes consistentes, devem adicionalmente proteger os pés contra penetração e esmagamento, com botas com biqueira e palmilha de aço.
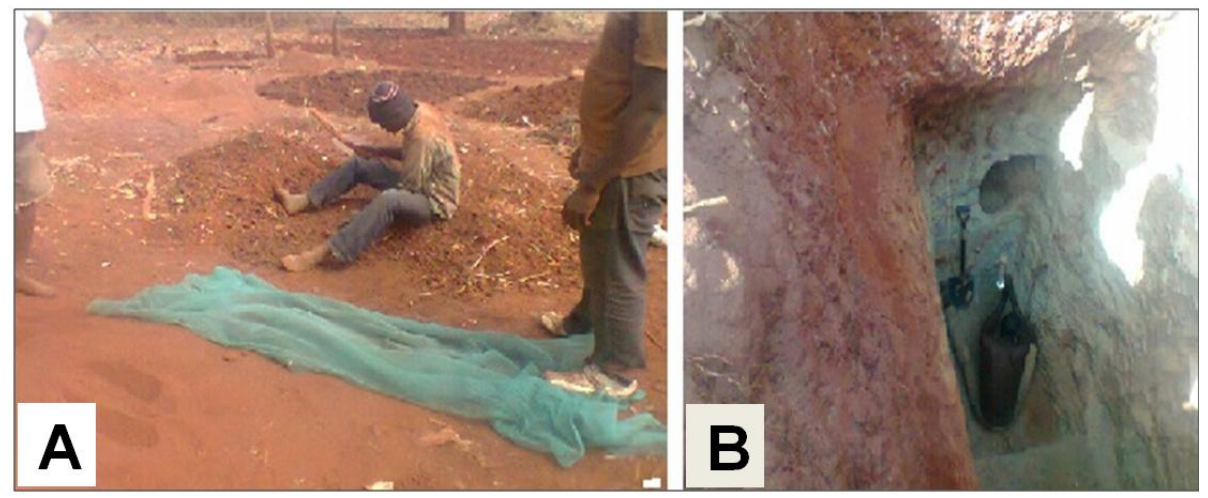

Figura 5: Garimpeiros em plena atividade de garimpo na mina de Nanhupo (A) e na mina de Nséue (B) Fonte: Trabalho de campo (Abril /2013) Autor: Bata, Eduardo (2013).

O garimpo das pedras preciosas contribui decisivamente para a degradação do ambiente local, pois acarreta a destruição da vegetação, a erosão dos solos, o assoreamento dos rios, o desvio do leito dos rios, e contaminação destes. Em Nanhupo e Nséue, os principais problemas ambientais resultantes do garimpo são: a destruição da vegetação nativa, erosão dos solos e o assoreamento dos solos.

De acordo com os dados da pesquisa de campo, 41 garimpeiros, ou seja, 83,7\% referiu-se a destruição da vegetação e 47 garimpeiros, o correspondente a 95,9\%, apontou o assoreamento dos rios como sendo o principal problema das aldeias desde o início da exploração das pedras preciosas e semipreciosas. Em relação aos efeitos negativos da exploração das pedras preciosas e outros minerais em Moçambique, Almeida et al., (2013, p. 87) colocam que,

[...] o garimpo traz consigo vários problemas: ambientais, sociais e econômicos. A título de exemplo, refere-se às crianças, que aliciadas pelo rendimento imediato, abandonam as aulas para se dedicarem a esta atividade, as mortes por soterramento e os casos de contaminação com produtos químicos usados no processo de lavagem dos minérios, sem quaisquer medidas de proteção, a erosão dos solos, aos problemas de saúde pública, causados pelo assoreamento dos rios e turvação das águas. 
Em Nanhupo e Nséue assim como em todo o Posto Administrativo, a comercialização das pedras preciosas é dominada por compradores estrangeiros ilegais, sobretudo tanzanianos, nigerianos, somalis, senegaleses e um pequeno grupo de moçambicanos. As pedras preciosas extraídas nas duas aldeias são vendidas nas cidades de Pemba, Montepuez, Nampula e em Namanhumbir- sede, local onde se concentram os principais intermediários deste negócio.

Ressaltando a importância da Sede do Posto Administrativo de Namanhumbir na comercialização das pedras preciosas, o Entrevistado Técnico (ET 1), garantiu que,

[...] os garimpeiros vendem as suas pedras lá mesmo em Namanhumbir, por que é lá onde está o mercado [...], se reparou quando vinha aqui um pouco depois de Nicocue tem um grande mercado, é ali onde se vende tudo [...] alguns garimpeiros vendem também aqui na cidade, principalmente, lá no Litos [nome do proprietário de uma casa de hóspedes, na qual se concentram grande parte dos estrangeiros e nacionais no fim do dia].

\section{A população de Nanhupo, Nséue e a percepção dos problemas ambientais do garimpo}

Em Namanhumbir, os maiores aglomerados populacionais localizam-se ao longo da Estrada Nacional (EN) n.242, que liga a cidade de Pemba ao Distrito de Montepuez. A principal atividade da população das duas aldeias é a agricultura; porém, com a descoberta do rubi em 2008, parte expressiva da população, sobretudo jovens, passou a trabalhar na exploração das pedras preciosas, devido aos rendimentos relativamente altos proporcionados pelo garimpo, Tal como explicou o Entrevistado Diretor (ED) que, esta atividade, embora de risco, ela é altamente lucrativa [...] imagina só [...],

Esta atividade, embora de risco, ela é altamente lucrativa [...] imagina só [...] uma pequena quantidade do mineral, por exemplo, $1 \mathrm{~g}$ do rubi é suficiente para ter o dinheiro que a agricultura não consegue dar nem mesmo em duas ou três campanhas [safras] bem sucedidas, a mineração proporciona renda elevada em comparação com a agricultura que é tida como uma atividade de atraso pela população.

No concernente aos problemas que afetam a população, de modo geral, a população de Namanhumbir, principalmente a das aldeias de Nanhupo e Nséue enfrenta: o baixo índice de cobertura no abastecimento de água; falta de emprego; de unidades sanitárias; escolas, sobretudo do ensino secundário, entre outros problemas. Em relação aos níveis de cobertura no abastecimento de água, dados do INE (2012) apontam que, o abastecimento de água a partir das fontes convencionais (fontenário, poço com bomba manual, torneira 
dentro e fora de casa) cobre apenas $20,6 \%$ da população total do Distrito, ao restante, o fornecimento de água é feito a partir de poços a céu aberto e sem bomba manual, água dos rios, lagos e lagoas, água da chuva entre outras fontes.

Na Figura 6 , pode-se observar que apenas $16 \%$ dos moradores das duas aldeias têm acesso à água potável a partir das fontes convencionais, $68 \%$ desta população consome água proveniente dos poços a céu aberto, $12 \%$ usa a água dos rios, lagos e lagoas e $4 \%$ utiliza a água proveniente de outras fontes não especificadas.

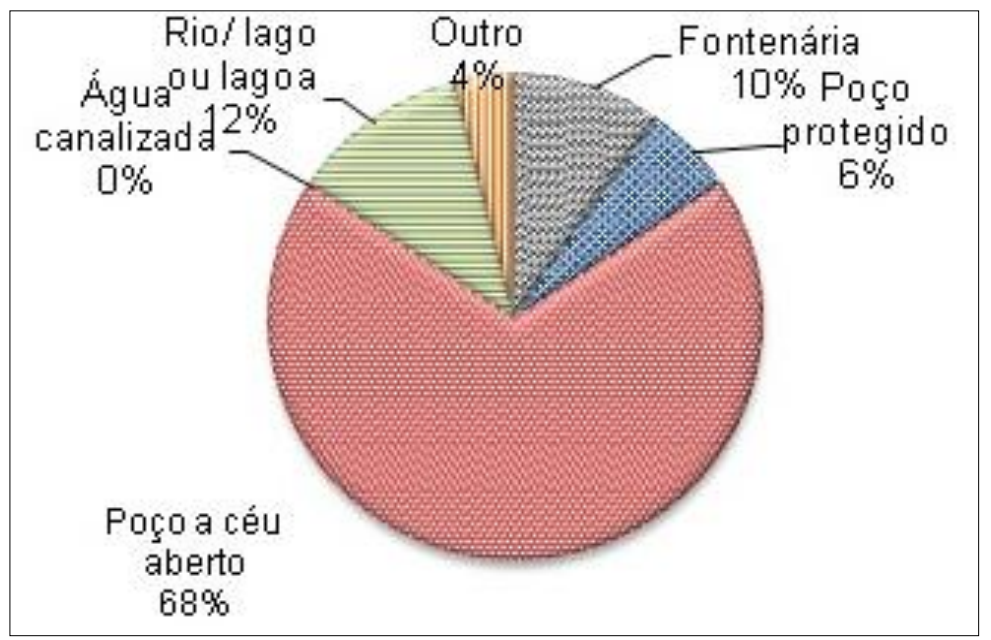

Figura 6: Local de abastecimento de água para o consumo e outras atividades dos moradores de Nanhupo e Nséue

Fonte: Trabalho de campo (Abril /2013).

Autor: Bata, Eduardo (2014).

O início da exploração das pedras preciosas e semipreciosas trouxe para Namanhumbir e, especialmente para as duas aldeias transformações socioespaciais e ambientais, cujos impactos são notórios no PAN. Dentre os problemas ambientais os mais salientes são: a depredação de grandes áreas de florestas, o desvio do leito dos rios para uso da água na lavagem e seleção das pedras preciosas, o assoreamento dos rios e poluição da água pela disposição de sedimentos descartados na mineração.

De acordo com os dados da pesquisa de campo, 47moradores, o equivalente a 95,9\% apontaram que o principal problema ambiental em Nanhupo e Nséue é a destruição da vegetação, enquanto isso, $79,6 \%$ referiu-se aos problemas da erosão, principalmente em Nséue, $83,7 \%$ apontou o barulho como o principal problema ambiental e 57,1\% destacaram o assoreamento e a contaminação dos rios como os problemas ambientais mais notórios nas duas aldeias. 
Assim, as áreas de maior incidência dos problemas ambientais foram as áreas de garimpo, o mercado de Namanhumbir sede e áreas residenciais, portanto, 38\% dos problemas ambientais apresentados pelos moradores ocorrem nas áreas de exploração das pedras preciosas (Nanhupo e Nséue), 34\% em áreas residenciais, e $20 \%$ nos rios locais.

No Distrito de Montepuez, o acesso à rede pública de esgoto sanitário abrange apenas a população que reside na zona de cimento, ou seja, o bairro urbano central. Deste modo, a população que reside nos bairros suburbanos- ou nos Postos Administrativos rurais - não tem acesso a estes serviços.

Segundo o Censo (2007), apenas 0,5\% da população total do Distrito têm as suas retretes ligadas à fossa séptica, portanto, o tipo de serviço sanitário predominante no Distrito é a latrina tradicional não melhorada (58\%); somente $2,5 \%$ tem latrina melhorada em suas habitações, ainda assim, 34,3\% da população não possui nenhum tipo de serviço sanitário em seus domicílios.

\section{CONCLUSÃO}

A pesquisa concluiu que há uma estreita relação entre a exploração das pedras preciosas, semipreciosas e a vulnerabilidade socioambiental dos moradores e garimpeiros de Nanhupo e Nséue, visto que esta atividade gera transformações socioespaciais e ambientais, tais como: a depredação das florestas, assoreamento e desvio do leito dos rios locais.

Do ponto de vista sociopolítico, o inicio do garimpo veio deteriorar as relações entre o Governo local e os moradores das duas aldeias, sobretudo depois da concessão das minas de Nséue e Nanhupo à Montepuez Ruby Mining, uma vez que a população local ainda reivindica a posse dessas minas.

Entretanto, apesar destes aspectos negativos, a exploração do rubi e da turmalina nessas aldeias, veio melhorar significativamente as condições de vida dos garimpeiros e dos moradores direita ou indiretamente envolvidos nesta atividade. A renda proveniente da venda dos minerais pelos garimpeiros permitiu a compra de alguns bens de uso tais como: rádio, motorizada, bem como a construção e/ou a reabilitação das suas habitações. 
Por outro lado, o inicio dessa atividade dinamizou o comércio local, sobretudo na Sede do Posto Administrativo e gerou alguns postos de trabalho ainda que temporários.

Apesar destes benefícios, as condições nas quais trabalham e vivem os garimpeiros e moradores de Nanhupo e Nséue são extremamente precárias, assim, a precariedade dos instrumentos de trabalho, os níveis de pobreza dos garimpeiros e dos moradores, aliado à falta de infraestruturas de apoio, como: hospitais, escolas, rede de abastecimento de água, rede de esgotos, entre outras infraestruturas básicas, expõem a comunidade local a riscos diversos. Haja vista que essas condições no seu conjunto corroboram para o alto índice de vulnerabilidade socioambiental $(3,86)$ verificado nas duas aldeias, reduzindo assim a capacidade de resposta dos moradores e garimpeiros, bem como do ambiente local.

\section{BIBLIOGRAFIA}

ADGER, W. N. Vulnerability: resilience, vulnerability, and adaptation: a cross-cutting theme of the international human dimensions programme on global environmental Change. Global Environmental Change, v.16, p. 268-281, 2006.

ALMEIDA, João C. Governação e integridade em Moçambique: problemas práticos e desafios reias. Maputo: Centro de Integridade Pública: Diname, 2013. 112p.

ALVES, H. P. da F. Vulnerabilidade sócio-ambiental na metrópole paulistana: uma análise das situações de sobreposição espacial de problemas e riscos sociais e ambientais. In: ENCONTRO DA ASSOCIAÇÃO NACIONAL DE PÓS-GRADUAÇÃO E PESQUISA EM PLANEJAMENTO URBANO E REGIONAL, 11., 2005, Salvador, Anais Salvador: UFB, 2005. p. 7 - 17.

AYRES, F. Vulnerabilidade e prevenção em tempos de Aids. In: BARBOSA. R.M E PARKER, R. Sexualidade pelo avesso: direitos, identidade e poder. ed. 34. São Paulo: Annablume Editora, 1999. Disponível em:< http://www.penelopeironstone.com/CottleBeckandMedia.pdf>, Acesso em: 11 fev. 2013.

DISTRITO DE MONTEPUEZ. Plano Estratégico de Desenvolvimento Distrital 2007- 2012. Montepuez, 2007.

ESTEVES, Claudio Jesus Oliveira de. Risco e vulnerabilidade socioambiental: aspectos conceituais. Caderno Ipardes, Estudos e Pesquisa, Curitiba, PR, v.1, n.2 p.62-79, dez. 2011.

FIGUEIRÊDO, Maria C. B. et al. Método de avaliação do desempenho ambiental de inovações tecnológicas agroindustriais: ambitec- ciclo de vida. Fortaleza; EMBRAPA, 121, p. 1- 63, 2009, (Documentos).

FIGUEIRÊDO, Maria C. B. et al. Análise da vulnerabilidade ambiental. Fortaleza. EMBRAPA, 127, p.1147, 2010, (Documentos).

GAMBA, Carolina. Avaliação da vulnerabilidade socioambiental dos distritos de município de São Paulo ao processo de escorregamento. 2011. 204f. Dissertação (Mestre em Geografia Humana), Departamento de Geografia da Faculdade de Filosofia e Letras da Universidade de São Paulo. São Paulo, 2011. 
HELTBERG, Rasmus; JORGENSEN, Steen Lau e BENNETT, Siegel. Addressing human vulnerability to climate change: Toward a 'no- regrets approach. The world Bank, United States, Global Environment Change, 19, 89-99, p. 2- 12, 2008.

HOGAN, Daniel Joseph, MARANDOLA JR, Eduardo. Vulnerabilidades e riscos: entre geografia e demografia. Revista Brasileira de Estudos de População, São Paulo, v. 22, n.1, p. 29-53, 2005.

INSTITUTO NACIONAL DE ESTATÍSTICA. III Recenseamento geral da população e habitação: indicadores sócio-demográficos, província de Cabo Delgado, Maputo, 2007.

METZGER, M. J et al. The vulnerability of ecosystem services to land use change. Agriculture, ecosystem and environment, 114, Netherlands, p. 1- 17, 2006.

MINISTÉRIO DA EDUCAÇÃO E CULTURA. Plano Estratégico de Educação e Cultura 2010-2016. Maputo: MEC, 2010.

MINISTÉRIO DA SAÚDE. Relatório sobre o acesso aos cuidados de saúde em Moçambique. Maputo: MISAU, 2010.

MOÇAMBIQUE. Política Nacional de Águas, de 2 de abril de 2008, publicado no Boletim da República (BR) I Série № 16, Maputo, 2 de abril de 2008.

. Lei no 14/2002, de 26 de junho de 2002, publicado no Boletim da República (BR), I Serie № 20, Maputo, 26 de junho de 2002.

MOSCA, João; SELEMANE, Tomás. El dorado Tete: os megaprojectos de mineração. Maputo: Centro de integridade pública, 2011. 30p.

SANTOS, Jader Oliveira de. Fragilidade e riscos socioambientais em Fortaleza-CE: contribuições ao ordenamento territorial. 2011.331f. Tese de (Doutorado em Geografia Física), Departamento de Geografia da Faculdade de Filosofia, Letras e Ciências Humanas da Universidade de São Paulo, São Paulo, 2011.

VILLA, F.; MCLEOD, H. Environmental vulnerability indicators for environmental planning and decision-making: guidelines and applications. Environmental management, v. 29, n. 3, p. 335-348, 2002.

WATERHOUSE, Rachel. Vulnerabilidade em Moçambique: padrões, tendências e respostas. Maputo, IESE, p. 1- 21, 2009.

\begin{tabular}{|r|r|}
\hline Artigo submetido em & $03 / 06 / 2014$ \\
\hline Artigo aceito em & 21/01/2015 \\
\hline
\end{tabular}

